\title{
Follicular dendritic cell sarcoma of the right tonsil: A case report and literature review
}

\author{
ZHONG-JIE LU ${ }^{1}$, JI LI ${ }^{2}$, SHUI-HONG ZHOU ${ }^{2}$, LI-BO DAI ${ }^{2}$, SEN-XIANG YAN ${ }^{1}$, \\ TING-TING $\mathrm{WU}^{2}$ and YANG-YANG BAO ${ }^{2}$ \\ Departments of ${ }^{1}$ Radiotherapy and ${ }^{2}$ Otolaryngology, The First Affiliated Hospital, \\ College of Medicine, Zhejiang University, Hangzhou, Zhejiang 310003, P.R. China
}

Received March 16, 2014; Accepted November 7, 2014

DOI: $10.3892 / \mathrm{ol} .2014 .2726$

\begin{abstract}
The current study presents a case of extranodal follicular dendritic cell sarcoma (FDCS) of the tonsil and reviews the relevant literature. In the present case, a 59-year-old male presented with a globus sensation in the right pharynx for 6 weeks. On clinical examination, a painless non-ulcerated enlarged right tonsil was identified; the tonsil was covered with a normal mucus membrane. A right tonsillectomy was performed under general anesthesia. The final pathological diagnosis was follicular dendritic cell sarcoma of the right tonsil.Postoperatively, the patient received radiotherapy. The patient remains alive without disease recurrence or metastasis 44 months after tonsillectomy. To the best of our knowledge, only 42 cases of FDCS of the tonsil have been reported to date. Of the 42 cases, 41 patients underwent surgery and one patient refused treatment. A total of $23(54.7 \%)$ received surgery alone. Adjuvant treatment was administered for 18 patients (42.9\%). Six patients (14.3\%) experienced local recurrences and two patients (4.8\%) succumbed to the disease 24 months after treatment. The three-, five-, and eight-year overall survival rates for the entire group were $86.5,77.8$ and $77.8 \%$, respectively. Furthermore, a tumor diameter of $\geq 4 \mathrm{~cm}$ was prognostic upon univariate analysis $\left(\chi^{2}=4.634 ; \mathrm{P}=0.031\right.$; excluding incomplete data). Tonsillar FDCS is rare and is associated with high rates of recurrence and metastasis, therefore, adjuvant treatment should be prescribed.
\end{abstract}

\section{Introduction}

Follicular dendritic cell sarcoma (FDCS) is a rare tumor, of which 200 cases (116 in the head and neck) have been reported in the English literature (1,2) since Monda et al (3) first described the condition in 1986. Extranodal FDCS of the head and neck

Correspondence to: Professor Shui-Hong Zhou, Department of Otolaryngology, The First Affiliated Hospital, College of Medicine, Zhejiang University, 79 Qingchun Road, Hangzhou, Zhejiang 310003, P.R. China

E-mail: zhouyunzhoush@163.com

Key words: follicular dendritic cell sarcoma, tonsil, treatment, prognosis, size of tumor occurs principally in the tonsils. To date, only cases in the English literature have been reviewed. In the present study, the Chinese literature regarding tonsillar FDCS is also reviewed.

The optimal therapeutic modality remains controversial as tonsillar FDCS is extremely rare. Although a wide surgical approach may be curative in certain patients, recurrences have been reported $(1,2)$. The efficacy of adjuvant therapy (chemotherapy or radiation) remains unclear $(1,2)$. De Pas et al (4) reported that chemoradiotherapy was ineffective when used to improve disease-free survival following radical tumor excision in 143 DCS cases with varying anatomical locations, which had been described in the English literature (4). Hu et al (2) reviewed 52 cases of FDCS in the pharyngeal region and found that postoperative adjuvant therapy increased disease-free patient survival compared with surgery alone (2). The identification of an optimal treatment modality requires further investigation using larger numbers of FDCS cases.

The current study presents a case of extranodal FDCS in the tonsil and reviews the relevant English and Chinese literature. Written informed consent for the publication of this study was obtained from the patient.

\section{Case report}

In March 2011, a 59-year-old male presented to the Department of Otolaryngology, The First Affiliated Hospital, College of Medicine, Zhejiang University (Hangzhou, China) with a globus sensation in the right pharynx that had persisted for six weeks. There was no history of fever, dysphagia, odynophagia, dyspnea, otalgia, hoarseness or trismus. The patient had a smoking history of $>20$ years (10 cigarettes per day) and had consumed alcohol (500 $\mathrm{ml}$ per day) for $>30$ years, however, the remaining medical history was uneventful. Upon clinical examination, a painless, non-ulcerated, enlarged right tonsil was identified, which was covered with a normal mucosal membrane. The nasopharynx, tongue, hypopharynx, larynx and cervical lymph nodes were normal. The initial clinical diagnosis was of right tonsillar lymphoma. Pharyngeal computed tomography $(\mathrm{CT})$ revealed a homogenously enlarged $4.6 \times 2.5 \times 2.5-\mathrm{cm}$ right tonsil, which was well-circumscribed. The initial enhancement value was $53 \mathrm{HU}$, and slight continuing heterogeneous enhancement was evident following the injection of contrast medium. The cervical lymph node 

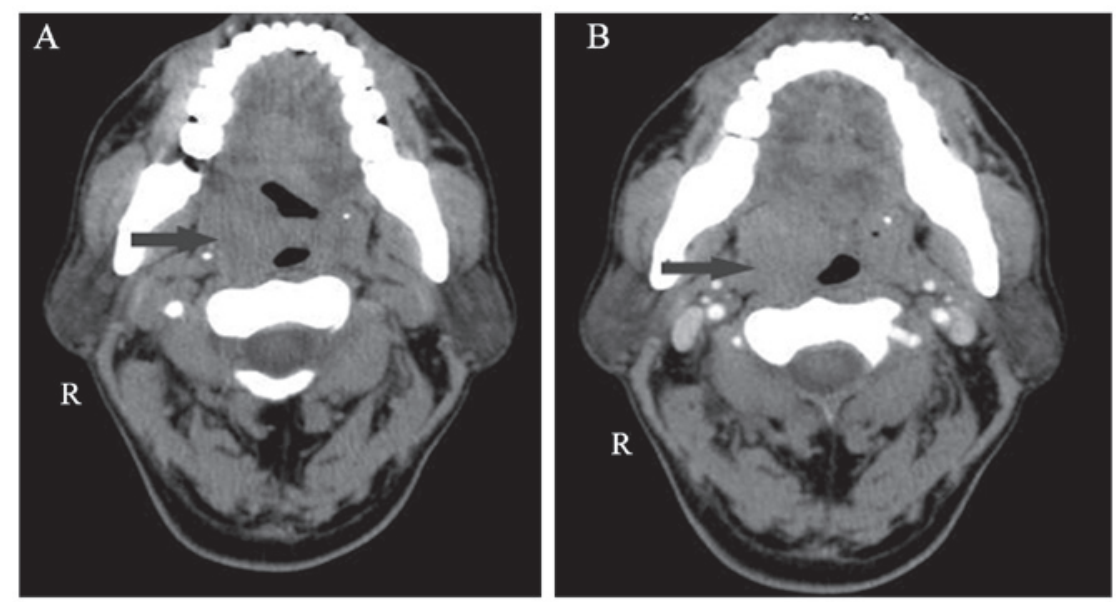

Figure 1. Computed tomography scans revealing a homogenously enlarged 4.6x2.5x2.5-cm right tonsil, which was well-circumscribed. (A) The initial enhancement value was $53 \mathrm{HU}$, and (B) slight continuing heterogeneous enhancement was evident following injection of contrast medium. R, right.
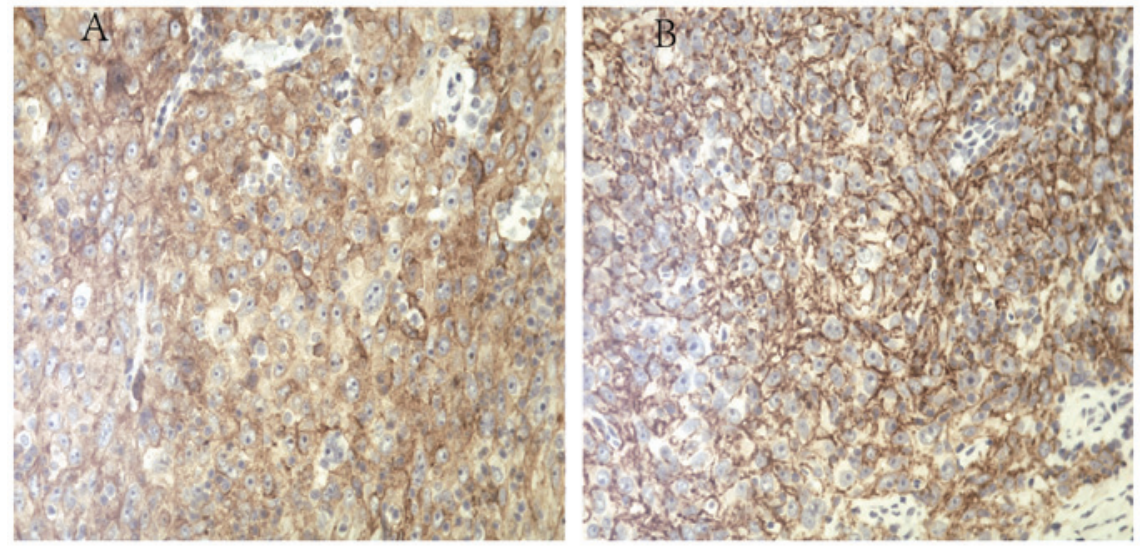

Figure 2. Pathological tests results showing a lesion containing large spindle-shaped heterogeneous cells forming solid or nested patterns, infiltrating the lymphoid stroma. Immunohistochemically, the cells were positive for (A) cluster of differentiation (CD)21 and (B) CD23.

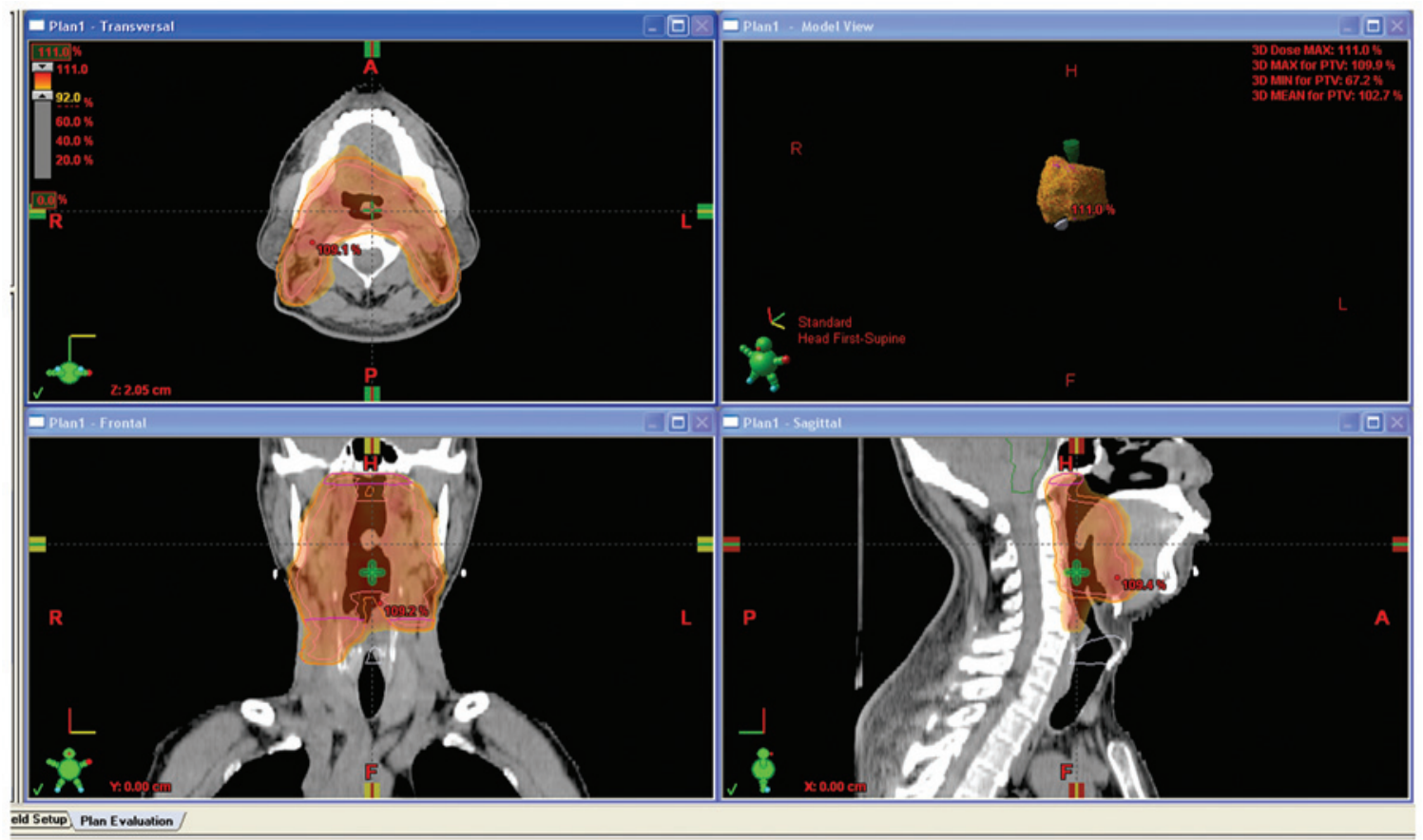

Figure 3. Postoperatively, the patient received radiotherapy (6,000 cGy in 200-cGy fractions delivered over 30 days) to the oropharyngeal and corresponding neck lymphatic regions. 
was not enlarged (Fig. 1). The CT observations indicated that the tumor could be a lymphoma. Ultrasonography of the abdomen and neck, and chest X-rays were unremarkable. A right tonsillectomy was performed under general anesthesia. Histological examination of frozen sections revealed the existence of a poorly-differentiated malignant tumor. Postoperative pathological tests showed that the lesion contained large spindle-shaped heterogeneous cells forming solid or nested patterns, infiltrating the lymphoid stroma. Immunohistochemically, the cells were positive for cluster of differentiation (CD)21 and CD23, and negative for CD3, CD10, CD20, CD30, CD35, anaplastic lymphoma kinase, and B-cell lymphoma 6 . The Ki-67 index was $20 \%$ (Fig. 2). Thus, FDCS of the right tonsil was diagnosed.

Postoperatively, the patient received radiotherapy (6,000 cGy in 200-cGy fractions over 30 days) to the oropharyngeal and neck lymphatic regions (Fig. 3). The patient remains alive without disease recurrence or metastasis 44 months after undergoing the tonsillectomy.

\section{Discussion}

Extranodal FDCS is rare. The etiology and the optimal treatment for extranodal FDCS remain unclear. In the present study, the English literature was reviewed using MEDLINE to conduct a PubMed/Web of Science search using the terms 'follicular dendritic cell tumor' or 'follicular dendritic cell sarcoma' combined with 'extranodal' or 'head and neck/tonsil/oropharynx/pharynx/pharyngeal region' (http://www.ncbi.nlm.nih.gov/pubmed). Articles published in the Chinese literature were found by searching the Wanfang (www.wanfangdata.com.cn), China National Knowledge Infrastructure (http://www.cnki.net/) and Weipu (http://10.15.61.77/index.asp) databases for studies published between 1986 and 2013. A total of 42 cases (including the present case) of FDCS were reported involving the tonsils; 29 cases were reported in the English literature (Table I) (2-27) and 13 cases were reported in the Chinese literature (Table II) (28-38). In the English literature, the study by Chan et al (27) was the first to describe tonsillar FDCS in 1994 (27). In the Chinese literature, the first case of FDCS of the tonsil was reported by Shi et al in 2004 (28). A decade ago, the disease entity was not well-documented and few immunohistochemical studies had been conducted (13).

Of the 42 patients reported, 22 were female and 19 were male; in one case, the gender of the patient was not reported. Of all the cases reported in the English literature, 15 patients were female and 14 were male. In the Chinese literature seven patients were female and five were male. The overall male to female ratio was $\sim 1.16: 1$ (English literature, 1.07:1; Chinese literature, 1.4:1). Similar to the results reported by Duan et al (9), the overall mean patient age was 48 years (range, 18-80 years) at initial presentation (English literature: mean, 50.0 years and range, 18-76 years; Chinese literature: mean, 43.5 years and range, 19-80 years); the age of one patient was not reported, . A total of 14 tumors were located in the left tonsil, while 20 were located in the right tonsil; the affected tonsil was not reported in eight cases. The mean tumor length was $3.1 \mathrm{~cm}$ (range, 0.8-6 cm), however, no data were available for 14 patients.

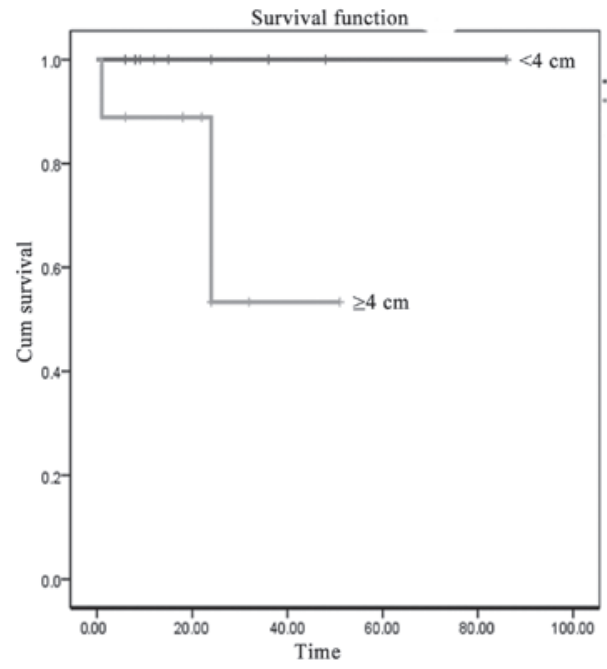

Figure 4. Univariate analysis results revealing that a tumor diameter of $\geq 4 \mathrm{~cm}$ was prognostic $\left(\chi^{2}=4.634 ; \mathrm{P}=0.031\right)$.

A total of 41 patients underwent surgery and one refused treatment. Of the 42 patients, 23 (54.7\%) received surgery alone. Adjuvant treatment was administered for 18 patients $(42.9 \%)$. This included postoperative radiotherapy for 17 patients $(40.5 \%)$, pre-operative radiotherapy for one patient $(2.4 \%)$, postoperative chemotherapy for four patients $(9.5 \%)$ and postoperative chemotherapy with radiotherapy for one patient $(2.4 \%)$. One patient received doxorubicin and ifosfamide (8), and one patient was administered a cyclophosphamide, Adriamycin, vincristine and prednisone regimen $(24,25)$. Details regarding the chemotherapy treatment were not provided in any studies from the Chinese literature. A total of five patients (11.9\%) underwent neck dissection.

Follow-up data were available for 36 patients $(85.7 \%)$, and the mean duration of follow-up was 36.6 months (range, 4 months to 15 years). A total of six patients (14.3\%) experienced local recurrence. At the final follow-up after treatment, 25 patients $(59.5 \%)$ were alive and disease-free, and eight patients (19.0\%) were alive with recurrent disease or metastasis. Two patients $(4.8 \%)$ succumbed to the disease 24 months after treatment, one patient (2.4\%) was lost to follow-up four years after tonsillectomy, one patient $(2.4 \%)$ was lost to follow-up after initial chemotherapy and follow-up data were not recorded for five patients (11.9\%). The three-, five- and eight-year overall survival rates for the entire group were $86.5,77.8$ and $77.8 \%$, respectively and the three-, five- and eight-year disease-free survival rates were 88.9, 76.2 and $57.2 \%$, respectively. The three-, five-, and eight-year overall survival and disease-free survival rates were similar, however, previous studies have contradicted these results. Li et al (10) reviewed 106 cases of extranodal FDCSs located throughout the body and reported that the two- and five-year overall survival rates were 82 and $79 \%$, respectively, and that the two- and five-year disease-free survival rates were 57 and $32 \%$, respectively. Duan et al (9) reviewed patients with extranodal FDCSs in the pharyngeal region and found that the recurrence, metastasis and mortality rates were $23.1 \%(9 / 39), 20.5 \%(8 / 39)$ and $2.6 \%(1 / 39)$, respectively. The three- and eight-year recurrence-free survival rates of the entire group were 74.8 and $24.6 \%$, respectively (9). As early as 1997, Chan et al (24) analyzed the 


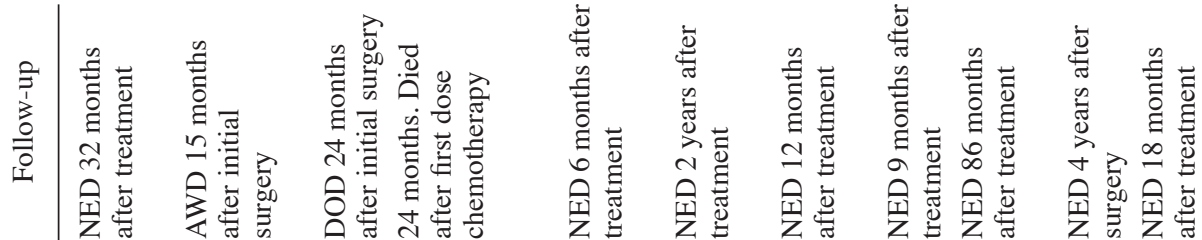

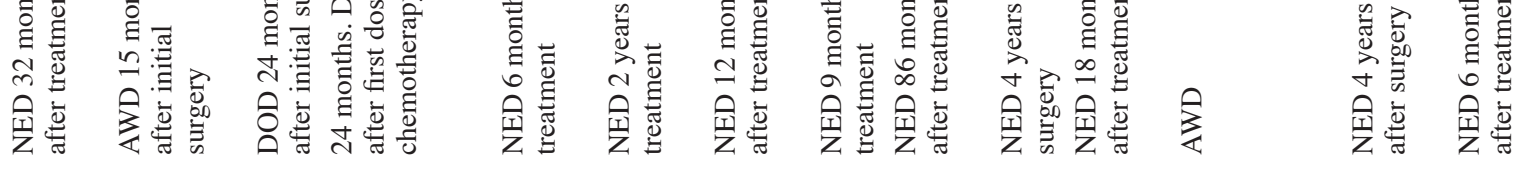

$\frac{2}{20}$

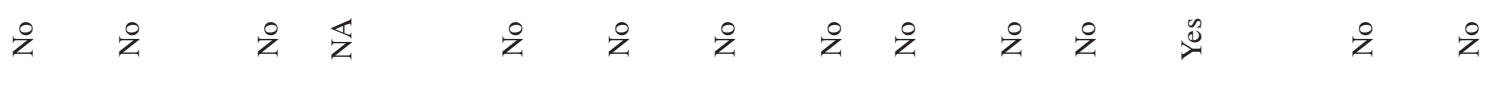

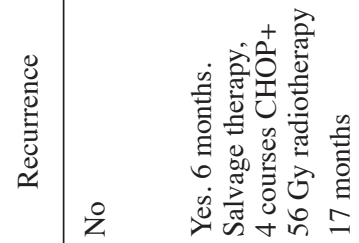

焉离

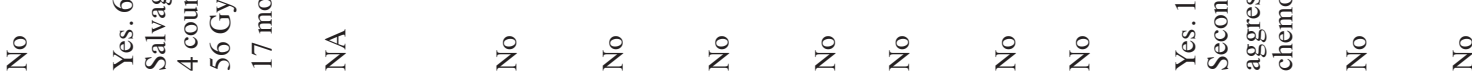

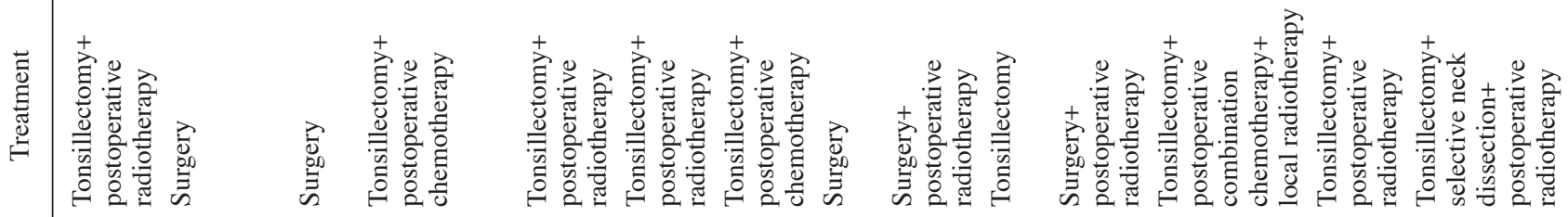

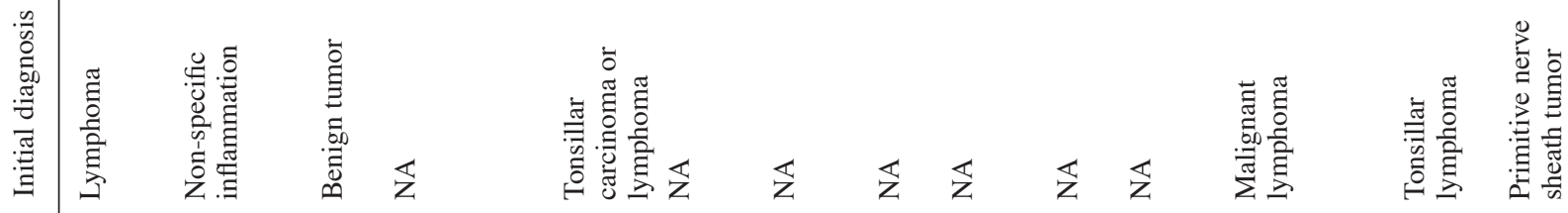

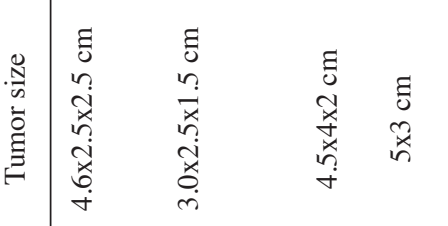

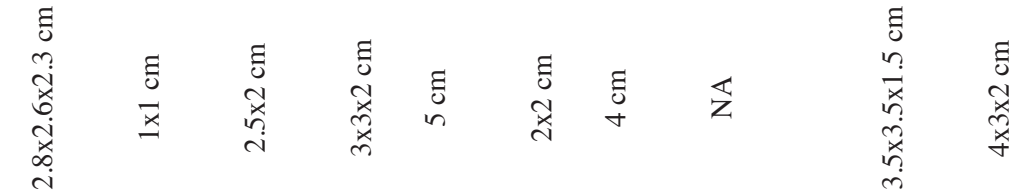

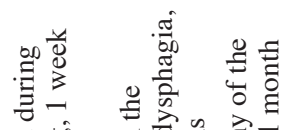

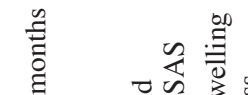

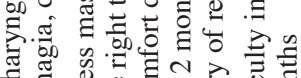

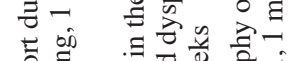

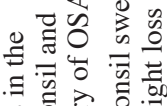

$\stackrel{0}{0}$

至

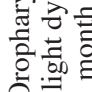

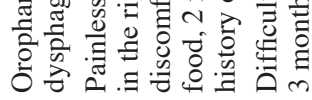

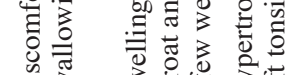

要

. 


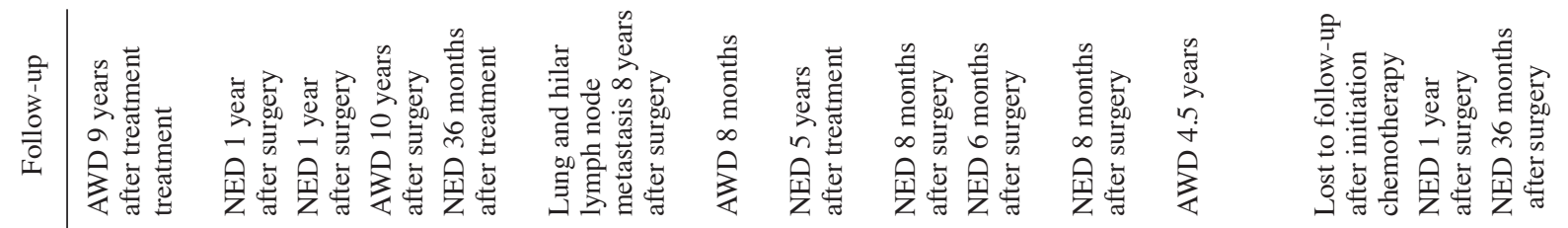

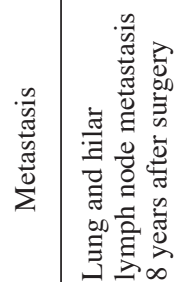

z

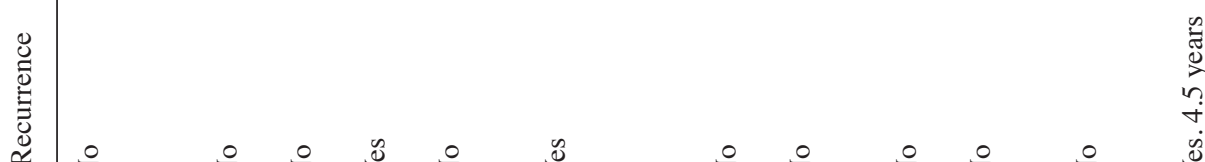

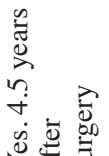

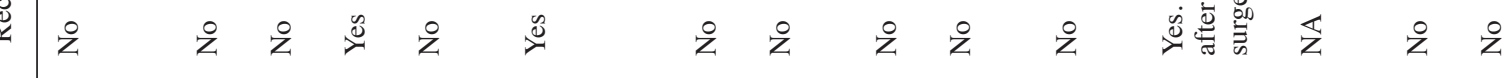

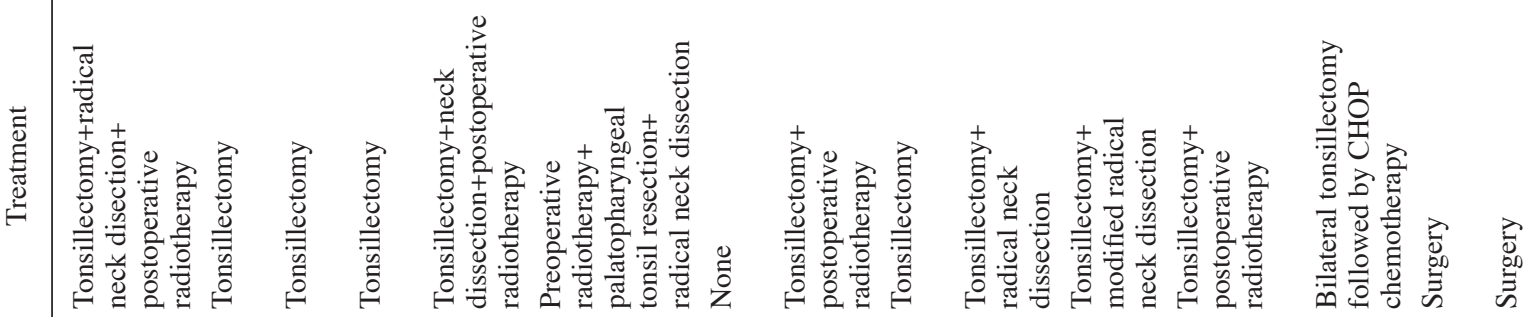

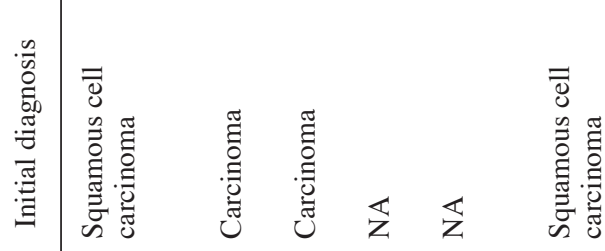

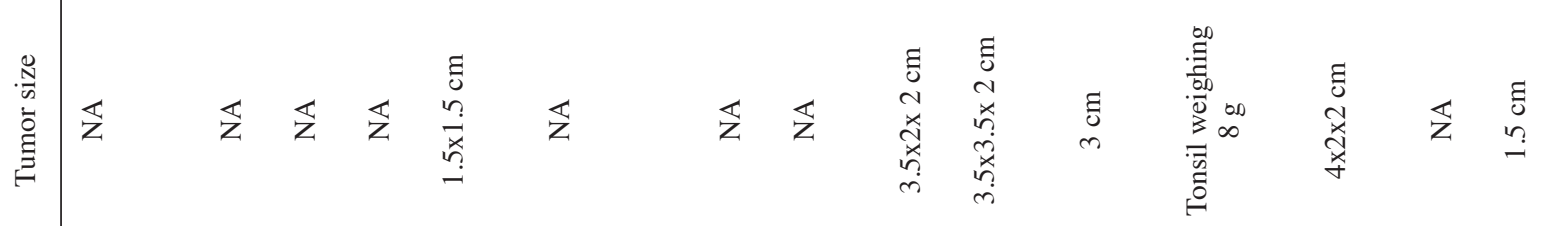

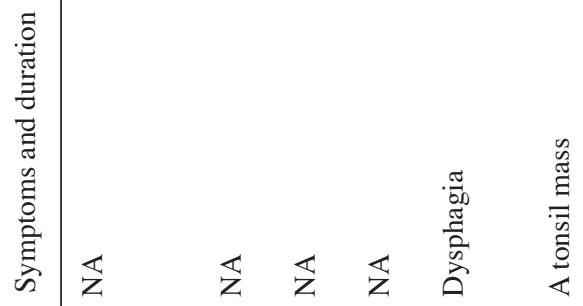

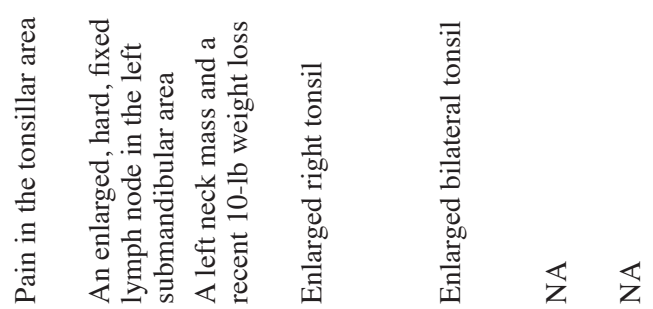

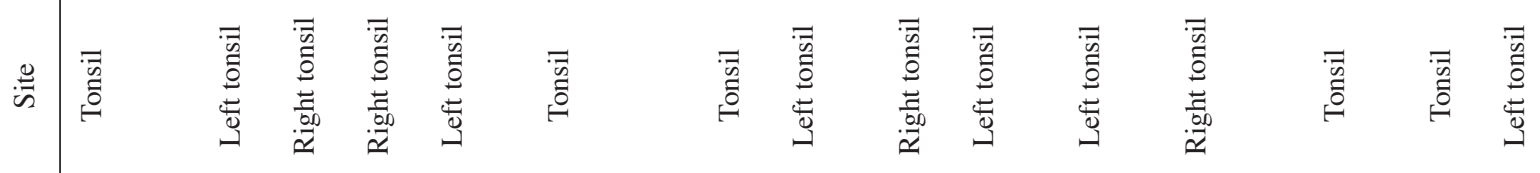

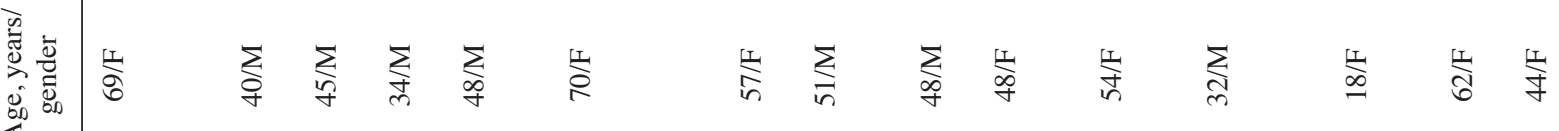




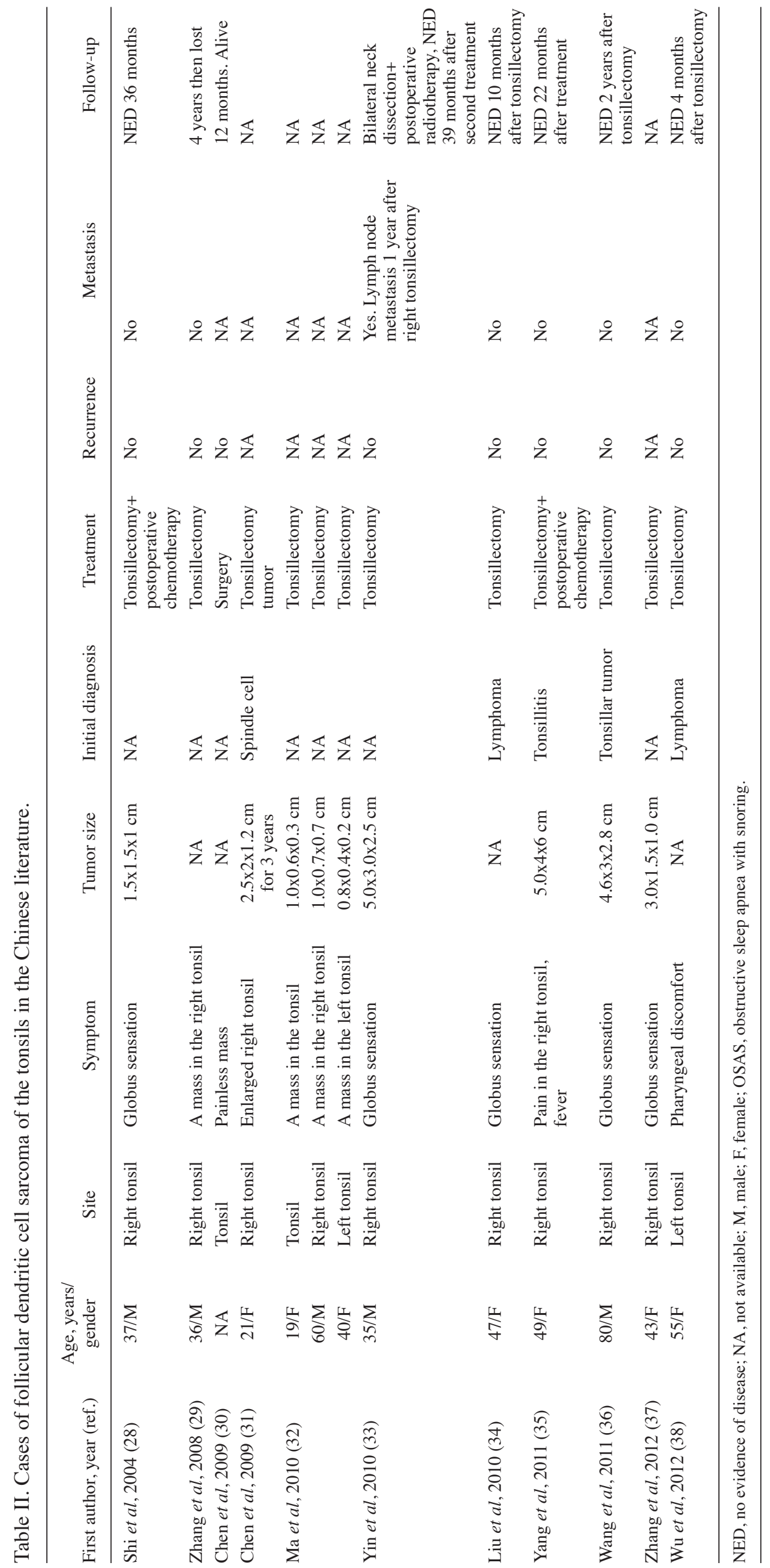


clinicopathological features of 17 cases of extranodal FDCS and found that the overall recurrence, metastasis and mortality rates were 43, 24 and $17 \%$, respectively. A possible reason for differences between the findings of the present study and that of previous studies may be that the present study focused on a single tumor site (the tonsil), thus excluding tumors in other extranodal sites, including the head and neck, pharyngeal region and other sites. Although prognostic factors remain unclear, the FDCS site is important, as patients with FDCSs in the parapharyngeal space exhibit poorer outcomes than those with other affected areas (2). Similarly, intra-abdominal lesions are associated with higher recurrence rates, which impacts patient survival (10).

Upon univariate analysis, it was found that a tumor diameter of $\geq 4 \mathrm{~cm}$ was prognostic $\left(\chi^{2}=4.634\right.$; $\mathrm{P}=0.031$; Fig. 4 ; incomplete data was excluded). The five-year survival rate in the combined treatment group $(87.9 \%)$ was higher than that in the surgery-alone group $(62.5 \%)$, however, this difference was not statistically significant $(\mathrm{P}=0.543)$. No statistically significant differences were identified between survival, recurrence and metastasis. Multivariate analysis revealed no statistically significant differences between survival and tumor size, treatment modality, recurrence or metastasis. In a study of extranodal FDCSs, Hu et al (2) also found that patients with large tumors ( $\geq 4 \mathrm{~cm}$ in diameter) in the pharyngeal region exhibited a worse prognosis compared with those with smaller tumors (2). The study also found that postoperative adjuvant therapy appeared to prolong the disease-free interval compared with surgery alone (2). Leipsic et al (39) found that an intra-abdominal tumor location, a tumor diameter of $\geq 6 \mathrm{~cm}$, a mitotic count of $\geq 5 / 10$ high-power fields, extensive coagulative necrosis, significant nuclear pleomorphism and a lack of adjuvant therapy, were all significant negative prognostic factors in patients with FDCSs of the mediastinum. However, the present review may be incomplete, due to certain data being unavailable (as can be observed in Table I), which would affect the results.

Tonsillar FDCS is rare and is associated with high rates of recurrence and metastasis. However, the present patient received tonsillectomy and postoperative radiotherapy, and remains alive without disease recurrence or metastasis after 44 months. Therefore, we hypothesize that adjuvant treatment should be prescribed.

\section{Acknowledgements}

This study was supported by the National Natural Science Foundation of China (grant nos. 81172562 and 81372903).

\section{References}

1. Karligkiotis A, Contis D, Bella M, et al: Pediatric follicular dendritic cell sarcoma of the head and neck: a case report and review of the literature. Int J Pediatr Otorhinolaryngol 77: 1059-1064, 2013.

2. Hu T, Wang X, Yu C, et al: Follicular dendritic cell sarcoma of the pharyngeal region. Oncol Lett 5: 1467-1476, 2013.

3. Monda L, Warnke R and Rosai J: A primary lymph node malignancy with features suggestive of dendritic reticulum cell differentiation. A report of 4 cases. Am J Pathol 122: 562-572, 1986.

4. De Pas T, Spitaleri G, Pruneri G, et al: Dendritic cell sarcoma: an analytic overview of the literature and presentation of original five cases. Crit Rev Oncol Hematol 65: 1-7, 2008.

5. Kara T, Serinsoz E, Arpaci RB and Vayisoglu Y: Follicular dendritic cell sarcoma of the tonsil. BMJ Case Rep 2013: bcr2012007440, 2013.
6. Mondal SK, Bera H, Bhattacharya B and Dewan K: Follicular dendritic cell sarcoma of the tonsil. Natl J Maxillofac Surg 3: 62-64, 2012.

7. Eun YG, Kim SW and Kwon KH: Follicular dendritic cell sarcoma of the tonsil. Yonsei Med J 51: 602-604, 2010.

8. Suhail Z, Musani MA, Afaq S, et al: Follicular dendritic cell sarcoma of tonsil. J Coll Physicians Surg Pak 20: 55-56, 2010.

9. Duan GJ, Wu F, Zhu J, et al: Extranodal follicular dendritic cell sarcoma of the pharyngeal region: a potential diagnostic pitfall, with literature review. Am J Clin Pathol 133: 49-58, 2010.

10. Li L, Shi YH, Guo ZJ, et al: Clinicopathological features and prognosis assessment of extranodal follicular dendritic cell sarcoma. World J Gastroenterol 16: 2504-2519, 2010.

11. Vaideeswar P, George SM, Kane SV, Chaturvedi RA and Pandit SP: Extranodal follicular dendritic cell sarcoma of the tonsil-case report of an epithelioid cell variant with osteoclastic giant cells. Pathol Res Pract 205: 149-153, 2009.

12. McDuffie C, Lian TS and Thibodeaux J: Follicular dendritic cell sarcoma of the tonsil: a case report and literature review. Ear Nose Throat J 86: 234-235, 2007.

13. Fan YS, Ng WK, Chan A, et al: Fine needle aspiration cytology in follicular dendritic cell sarcoma: a report of two cases. Acta Cytol 51: 642-647, 2007.

14. Aydin E, Ozluoglu LN, Demirhan B and Arikan U: Follicular dendritic cell sarcoma of the tonsil: case report. Eur Arch Otorhinolaryngol 263: 1155-1157, 2006.

15. Clement P, Saint-Blancard P, Minvielle F, Le Page P and Kossowski M: Follicular dendritic cell sarcoma of the tonsil: a case report. Am J Otolaryngol 27: 207-210, 2006.

16. Shia J, Chen W, Tang LH, et al: Extranodal follicular dendritic cell sarcoma: clinical, pathologic, and histogenetic characteristics of an underrecognized disease entity. Virchows Arch 449: 148-158, 2006.

17. Bothra R, Pai PS, Chaturvedi P, et al: Follicular dendritic cell tumour of tonsil-is it an under-diagnosed entity? Indian J Cancer 42: 211-214, 2005.

18. Domínguez-Malagón H, Cano-Valdez AM, Mosqueda-Taylor A and Hes O: Follicular dendritic cell sarcoma of the pharyngeal region: histologic, cytologic, immunohistochemical, and ultrastructural study of three cases. Ann Diagn Pathol 8: 325-332, 2004

19. Idrees MT, Brandwein-Gensler M, Strauchen JA, et al: Extranodal follicular dendritic cell tumor of the tonsil: report of a diagnostic pitfall and literature review. Arch Otolaryngol Head Neck Surg 130: 1109-1113, 2004.

20. Grogg KL, Lae ME, Kurtin PJ and Macon WR: Clusterin expression distinguishes follicular dendritic cell tumors from other dendritic cell neoplasms: report of a novel follicular dendritic cell marker and clinicopathologic data on 12 additional follicular dendritic cell tumors and 6 additional interdigitating dendritic cell tumors. Am J Surg Pathol 28: 988-998, 2004.

21. Tisch M, Hengstermann F, Kraft K, von Hinüber G and Maier H: Follicular dendritic cell sarcoma of the tonsil: report of a rare case. Ear Nose Throat J 82: 507-509, 2003.

22. Biddle DA, Ro JY, Yoon GS, et al: Extranodal follicular dendritic cell sarcoma of the head and neck region: three new cases, with a review of the literature. Mod Pathol 15: 50-58, 2002.

23. Vargas H, Mouzakes J, Purdy SS, et al: Follicular dendritic cell tumor: an aggressive head and neck tumor. Am J Otolaryngol 23: 93-98, 2002.

24. Chan JK, Fletcher CD, Nayler SJ and Cooper K: Follicular dendritic cell sarcoma: Clinicopathologic analysis of 17 cases suggesting a malignant potential higher than previously recognized. Cancer 9: 294-313, 1997.

25. Nayler SJ, Verhaart MJ and Cooper K: Follicular dendritic cell tumour of the tonsil. Histopathology 28: 89-92, 1996.

26. Perez-Ordonez B, Erlandson RA and Rosai J: Follicular dendritic cell tumor: report of 13 additional cases of a distinctive entity. Am J Surg Pathol 20: 944-955, 1996.

27. Chan JK, Tsang WY, Ng CS, et al: Follicular dendritic cell tumors of the oral cavity. Am J Surg Pathol 18: 148-157, 1994.

28. Shi QL, Zhou XJ, Ma J, et al: Follicular dendritic cell sarcoma of tonsil: a case report and review of the literature. Zhen Duan Bing Li Xue Za Zhi 11: 81-83, 2004 (In Chinese).

29. Zhang ZX, Cheng J, Shi QL, et al: Follicular dendritic cell sarcoma a clinicopathologic study of 8 cases. Zhong Hua Bing Xue Za Zhi 37: 395-399, 2008 (In Chinese).

30. Chen YP, Chen G, Lin J, et al: Clinicopathologic analysis of four cases of extranodal follicular dentritic cell sarcoma. Bai Xue Bing Lin Ba Liu 18: 619-621, 2009 (In Chinese). 
31. Chen YH, Luo KS, Jian Y, Luo Y and Fan YY: Follicular dendritic cell sarcoma: A clinicopathologic study of 4 cases. Zhong Guo Zhong Liu Lin Chuang 36: 901-904, 2009 (In Chinese).

32. Ma SR, Li KC, Xu YQ, et al: Follicular dentritic cell sarcoma: a clinicopathologic analysis of 6 cases. Lin Chuang Yu Shi Yan Bing Li Xue Za Zhi 26: 565-568, 2010 (In Chinese).

33. Yin WH, Yu GY, Ma Y, et al: Follicular dendritic cell sarcoma a clinicopathologic analysis of ten cases. Zhong Hua Bing Xue Za Zhi 39: 522-527, 2010 (In Chinese).

34. Liu BA, Wang HW, Zhao L, Chen H, Liu LJ and Su ZS: Follicular dendritic cell sarcoma a clinicopathologic analysis of five cases. Zhen Duan Bing Li Xue Za Zhi 17: 182-185, 189, 2010 (In Chinese).

35. Yang LH, Zhang AH, Wang WF, Wang FC and Chen FY: Follicular dendritic cell sarcoma of tonsil: a case report. Zhong Guo Shi Yan Zhen Duan Xue 15: 1215-1216, 2011 (In Chinese).
36. Wang Q, An LF, Cui N, Sha JC and Zhu DD: Follicular dendritic cell sarcoma: a case report and review of literature. Lin Chuang Er Bi Yan Hou Ke Za Zhi 25: 100-102, 2011 (In Chinese).

37. Zhang LJ, Li M and Chen Y: Follicular dendritic cell sarcoma of tonsil: a case report. Shi Yong Yi Xue Za Zhi 28: 2804, 2012 (In Chinese).

38. Wu $\mathrm{HB}$, Chen $\mathrm{K}, \mathrm{Hu} \mathrm{W}$ and Wang XQ: Epithelioid follicular dentritic cell sarcoma of the tonsil: case report and review of the literature. Xian Dui Zhong Liu Yi Xue 20: 1581-1584, 2012 (In Chinese)

39. Leipsic JA, McAdams HP and Sporn TA: Follicular dendritic cell sarcoma of the mediastinum. AJR Am J Roentgenol 188: 554-556, 2007. 